\title{
RESEARCH
}

\section{The consequences of waiting for cataract surgery: a systematic review}

\author{
William Hodge, Tanya Horsley, David Albiani, Julia Baryla, Michel Belliveau, Ralf Buhrmann, \\ Michael O'Connor, Jason Blair, Elizabeth Lowcock
}

\section{ABSTRACT}

Background: Cataract surgery is the most common operative procedure performed in Canada, and how patients are affected by wait times for this surgery has important clinical, public health and health policy considerations. We conducted a systematic review to understand the relation between wait time for cataract surgery and patient outcomes and the variables that modify this relation.

Methods: We performed an electronic search of 11 databases and the proceedings of 4 conferences. The search was restricted to studies published after the transition to phacoemulsification (1990). We assessed the quality of the included studies using the Jadad Scale for randomized controlled trials and the Newcastle-Ottawa Scale for cohort and case-control studies. The data were found to be inappropriate for meta-analysis, thus we performed a qualitative synthesis.

Results: We found a total of 27 studies that met our inclusion criteria. When these studies were reviewed, a dichotomy was observed for the wait time-outcome relation: outcomes associated with wait times of $\leq 6$ weeks were better than outcomes associated with wait times of $\geq 6$ months. Patients who waited more than 6 months to receive cataract surgery experienced more vision loss, a reduced quality of life and had an increased rate of falls compared with patients who had wait times of less than 6 weeks. The outcomes associated with wait times between 6 weeks and 6 months remain unclear.

Interpretation: Patients who wait more than 6 months for cataract surgery may experience negative outcomes during the wait period, including vision loss, a reduced quality of life and an increased rate of falls.

CMAJ 2007;176(9):1285-90

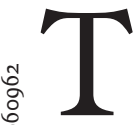
he number of cataract surgeries performed in Ontario doubled between 1993 and $2003^{1}$ and is projected to continue to increase since up to $21 \%$ of the population will be over 65 years of age by the year 2026. Cataracts are the most common eye disorder in North America: about $50 \%$ of people between 55 and 64 years of age and $85 \%$ of people over 75 years of age will develop cataracts within a Ioyear period. ${ }^{2}$ Cataract surgery has a high level of efficacy, has minimal complications and is convenient for patients. Combined with the age-related demographic shift, these factors have led to a level of demand for this procedure that exceeds supply in many areas of the country.

The Canadian federal and provincial governments have identified sight restoration as I of the 5 priority areas for developing evidence-based benchmarks for medically acceptable wait times. To set such wait times, we need to understand the relation between wait time and outcomes and to identify variables that modify this relation. Cataract surgery is the sight-restoration procedure with the greatest public health importance; thus, we systematically reviewed the body of literature addressing wait time and patient outcomes and asked 2 key questions: What is the relation between wait times and typical cataract-related outcomes? What variables modify this relation?

\section{Methods}

We developed and refined the key research questions through an iterative process involving a technical expert panel. The panel was also involved in defining the primary patient outcomes and the patient characteristics to be analyzed. We identified 3 broad categories of outcomes: visual, adverse event and quality of life.

An information specialist, in consultation with clinical content experts in ophthalmology, developed an electronic search strategy that was used to search MEDLINE (2005 May week 3), HealthSTAR (May 2005), EMBASE (2005 week 23), CENTRAL, the Cochrane Database of Systematic Reviews (The Cochrane Library, Issue 2, 2005), EconLit (May 2005), NHS Economic Evaluation Database, Health Technology Assessment Database, Canadian Business and Current Affairs, Scopus, TRIP and the Cochrane Effective Practice and Organization of Care registry. We performed the database search on June 22, 2005, except where noted. The technical expert panel also identified conferences that may have been relevant to the study questions, including the Association for Research in Vision and Ophthalmology, the American Academy of Ophthalmology, the European Association for Vision and Eye Research and the Canadian Ophthalmology Society. We reviewed the proceedings of these conferences to identify any relevant unpublished reports.

We restricted the literature search to studies published after the transition to the modern method of cataract surgery 
(phacoemulsification), which occurred around 1990 in Western countries, including Canada. We included studies performed in Canada or comparable regions (e.g., United Kingdom, Australia) to maximize the interpretability and generalizability of our review. In addition, standardized and accepted assessment methods (e.g., slit lamp examination) and diagnostic criteria (e.g., Snellen or Early Treatment Diabetic Retinopathy Study [ETDRS] acuity) must have been used for study inclusion. However, inclusion was not determined by the definition of wait time used by the authors. All included studies addressed cataract removal among adults.

All of the bibliographic records that we identified were posted to a secure Internet-based software program for

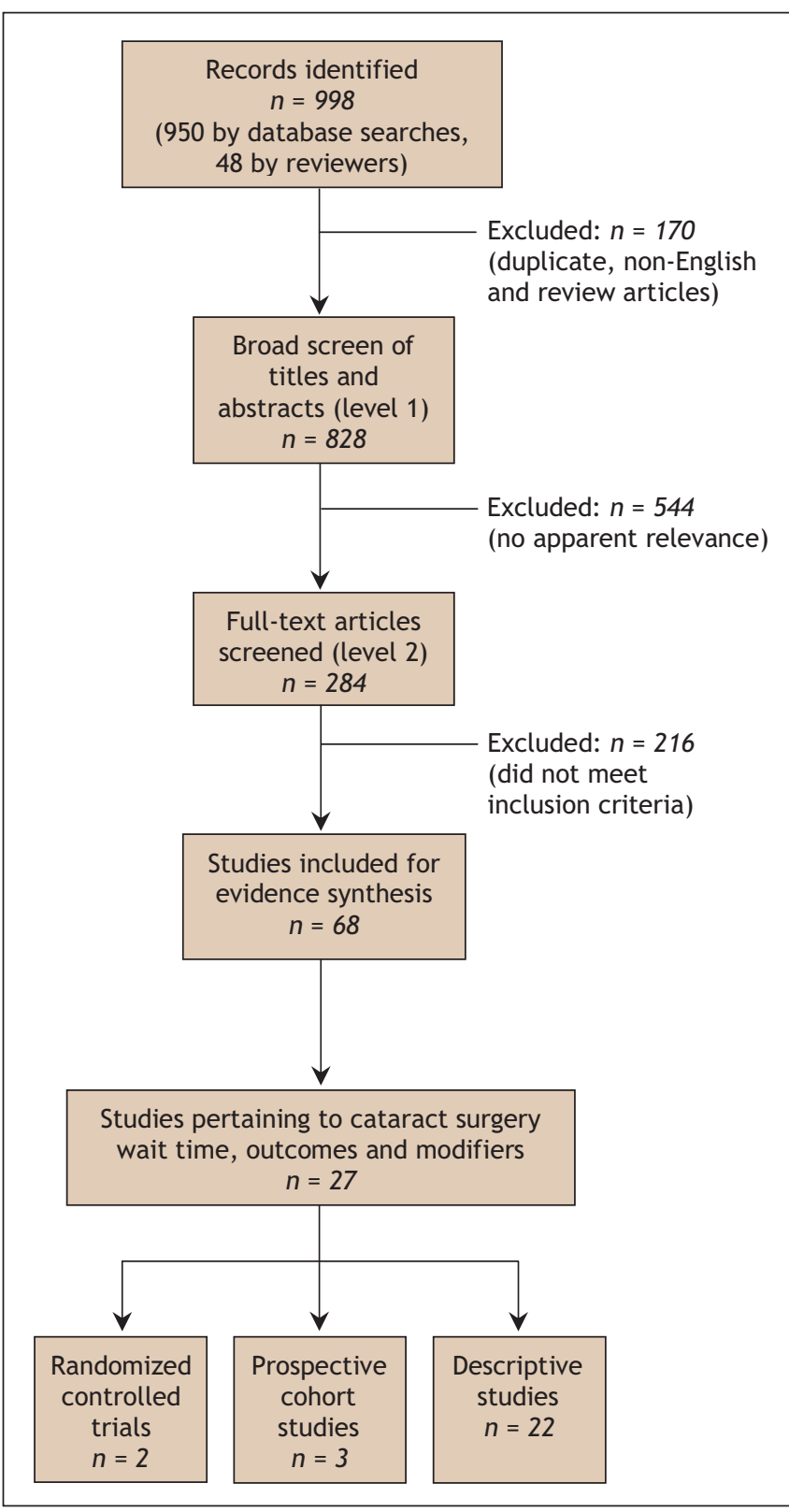

Fig. 1: Quality of Reporting of Meta-analysis (QUOROM) flow chart showing the number of studies screened and included in the systematic review. review. We developed screening questions to assess the level of study relevance and performed a calibration exercise to determine consensus. Initially, we performed a broad screen of study titles and abstracts to determine relevance. Studies identified as being potentially relevant were retrieved in fulltext format and were screened independently by 2 of us (D.A and M.O). When disagreement occurred, consensus was achieved through discussion or consultation by a third party. We used a Quality of Reporting of Meta-analysis (QUOROM) flow diagram ${ }^{3}$ to record the reasons for exclusion for ineligible studies (Fig. I).

Data abstractors independently extracted information from the included studies using forms that were developed for and tailored specifically to this review. The data extracted by one abstractor were verified by the second abstractor. We performed quality assessment using the Jadad Scale ${ }^{4}$ for randomized controlled trials and the Newcastle-Ottawa Scale ${ }^{5}$ for cohort and case-control studies. The Jadad scale assesses the quality of the reported methods of randomization, allocation concealment and accounting for withdrawals and dropouts. Scores vary from o to 5 , and studies that receive a score of less than 3 are considered to be of "low" quality. The Newcastle-Ottawa Scale uses a "star" rating system to judge quality based on 3 aspects of the study: selection of study groups, comparability of study groups and ascertainment of either the exposure or outcome of interest (dependent on assessment of case-control or cohort study respectively). The maximum number of stars a study may receive in each of these 3 categories is 4,2 and 3 respectively, for a total of 9 possible stars. The validity of these tools has been previously established. ${ }^{4,5}$

The data were examined and found to be inappropriate for meta-analysis. Thus, we performed a qualitative synthesis according to the 3 outcome categories of interest (visual, adverse event and quality of life) and potential modifiers.

\section{Results}

We found 27 articles that met our inclusion criteria. ${ }^{6-32}$ Thirteen of these studies examined the relation between wait time and outcomes, ${ }^{6-18}$ and Ig studies examined the variables that modified this relation. ${ }^{14-32}$ We included 2 randomized controlled trials, 3 prospective cohort studies and 22 descriptive studies. The design of the randomized controlled trials and cohort studies was suitable for quality assessment, and these studies carried the greatest interpretive value in this review. Ten of the 22 descriptive studies addressed our research questions directly, and their findings are discussed in the following text. In the included studies, wait time was typically defined as the length of time from surgical booking until the procedure was performed.

The results of the randomized controlled trials and prospective cohort studies that examined the relation between wait time and outcomes are shown in Table I. We did not identify any studies that compared postoperative visual outcomes after different lengths of wait times; however, multiple studies observed a decline in visual acuity over the course of the wait for surgery. In New Zealand, Riley and colleagues ${ }^{6}$ 
found that the vision of people waiting for surgery at a public hospital (mean wait I3.I months) declined from 6/30 to 6/36 (0.05 Logarithm of the Minimum Angle of Resolution units [LogMAR]), which was not statistically significant. A mean decline in vision of 0.27 LogMAR units (equivalent to a $33 \%-50 \%$ reduction in vision) was observed in Finland by Leinonen and colleagues ${ }^{7}$ after a 13 -month wait. In the United Kingdom, Laidlaw and colleagues ${ }^{8}$ found that 4 indications of visual acuity (distance, near reading, contrast sensitivity, stereoacuity) were significantly poorer among patients still waiting for second-eye cataract surgery at a 6-month followup visit than among patients who had received expedited surgery $(p<0.005)$. The differences in distance and reading LogMAR values were 0.063 (95\% confidence interval [CI] $0.035-0.090)$ and 0.047 (95\% CI $0.017-0.077$ ) respectively. ${ }^{8}$

Most of the publications included in our systematic review did not report any adverse health events associated with waiting for surgery; however, the explicit purpose of the randomized controlled trial carried out by Harwood and colleagues ${ }^{9}$ was to compare the risk of falling among elderly women who had received $(n=154)$ or were waiting for $(n=152)$ first-eye cataract surgery. During a I2-month period, I45 of the 306 study participants reported a total of 352 falls. The proportion of patients who fell did not differ between groups: $49 \%$ (76/154) of expedited patients and $45 \%(69 / 152)$ of control patients $(p=0.77)$. However, significantly fewer patients who received expedited surgery than patients still awaiting surgery fell 2 or more times (I8\% [28/I54] v. $25 \%$ [38/I52], $p=0.04)$. The rate ratio of falling was 0.66 (95\% CI $0.45-0.96)$. Patients who received expedited surgery also experienced fewer fractures than those awaiting surgery $(3 \%$ [4/I54] v. I2\% [12/152], $p=0.04) .{ }^{9}$

Several studies examined the influence of wait time on patient quality of life and satisfaction. The 2 randomized con- trolled trials carried out in the United Kingdom found significant improvement in quality-of-life indicators following expedited surgery. ${ }^{8,9}$ Harwood and colleagues ${ }^{9}$ observed that elderly women who received expedited first-eye cataract surgery (within 4 weeks) experienced a significantly higher quality of life than women awaiting routine surgery $(p<0.0005)$, as measured by the VF-I4 questionnaire (measures functional impairment caused by cataracts ${ }^{34}$ ). Women who received expedited first-eye cataract surgery also exhibited improved physical activity $(p=0.05)$ and confidence levels $(p<0.0005)$, and reduced levels of anxiety $(p=0.007)$ and depression $(p=0.003)$ compared with controls. ${ }^{9}$ A study of similar design by Laidlaw and colleagues ${ }^{8}$ found that participants who were randomly assigned to receive expedited second-eye surgery (within 6 weeks, compared with a routine wait of 7-I2 months) also experienced significant improvements in terms of 4 quality-of-life outcomes $(p<0.0001)$. Conversely, 2 European cross-sectional studies that compared the characteristics of patients undergoing cataract surgery at multiple centres with varying wait times found no relation between wait time and quality of life as measured by the VF-I4 questionnaire. ${ }^{10,14}$

Two randomized controlled trials present the highest quality data included in this review and found that patients who waited less than 6 weeks for cataract surgery experienced better visual and quality-of-life outcomes and fewer adverse events (falls) than patients who waited 6 months or longer.

Conner-Spady and colleagues ${ }^{15}$ explored the determinants of satisfaction with cataract surgery. Among patients in Vancouver who received cataract surgery, $88 \%$ were satisfied with the surgery. Satisfaction had a weak, but significant, association with wait time (Spearman $r=0.37, p<0.001$ ). ${ }^{15}$ Patients at public hospitals in Sydney, Australia, waited 9 times longer than patients at private hospitals for cataract surgery $(38$

Table 1: Summary of studies that examined the relation between wait time for cataract surgery and patient outcomes

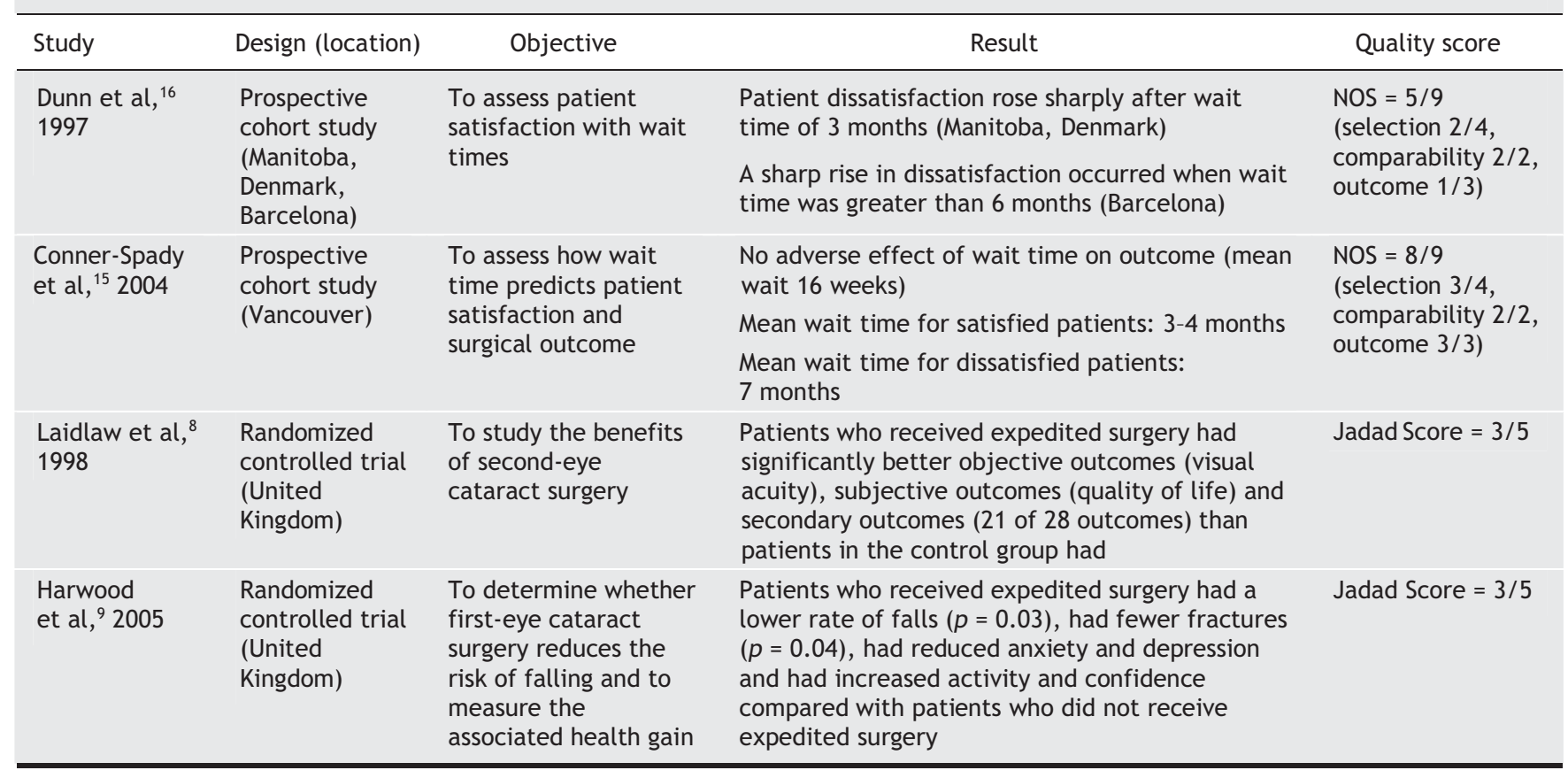


weeks v. 4 weeks) and were significantly less satisfied with their wait for surgery $(p<0.00 \mathrm{I}) .{ }^{11}$ Data from around the world indicated that patients were dissatisfied with longer wait times, yet it is interesting that, among the 3 international cohorts studied by Dunn and colleagues, ${ }^{16}$ the Canadian cohort expressed the greatest degree of dissatisfaction with longer wait times: people in the Manitoba cohort were more than twice as likely as people from Denmark, and 8 times as likely as people from Barcelona, to perceive anticipated waits of 3.I to 6 months as being too long (Manitoba, odds ratio [OR] 13.62, 95\% CI 4.55-40.79; Denmark, OR 6.18, 95\% CI 2.46-I5.54; Barcelona, OR I.67, 95\% CI 0.37-7.50). ${ }^{16}$

The results of the studies that examined the variables that modify the relation between wait time for cataract surgery and outcome are shown in Table $2 .{ }^{15-17}$ Variables that modify the relation have been identified by means of expert consensus and empirical investigation. To prioritize patients for cataract surgery, experts have identified various factors that they believe influence visual and quality-of-life outcomes. These modifiers have been incorporated into various priority scoring systems that are described in the literature. Variables incorporated into prioritization schemes, based on expert opinion, include visual acuity ${ }^{19-22}$ functional impairment (including work or driving), ${ }^{20-23}$ other eye pathology, ${ }^{19,20,22}$ other disability, ${ }^{19,20}$ age, ${ }^{20}$ need to care for dependents ${ }^{20}$ and length of wait. ${ }^{20,23}$

The Cataract Surgery Priority Criteria Tool is a prioritization tool developed by the Western Canada Waiting List Project and consists of the sum of 7 weighted priority criteria.
The criteria items include: best-corrected visual acuity in the nonsurgical eye, best-corrected visual acuity in the surgical eye, glare, ocular comorbidity, visual impairment, other disabilities, and ability to work, live independently and care for dependents. The validity of this tool in predicting patient benefit has been assessed, and the tool was found to be a significant predictor of improved visual function and visual acuity $(p<0.05)$, which indicates that these 7 criteria modify the relation between wait time and visual outcome. ${ }^{17}$

Two studies that examined the variables that influence patient satisfaction with wait time were identified, ${ }^{15,16}$ and the results are included in Table 2.

\section{Interpretation}

The amount of research into the relation between wait time for cataract surgery and patient outcomes, and the modifiers of this relation, is somewhat limited; however, the studies that we examined in this systematic review support the conclusion that patients may experience negative outcomes during the wait for this procedure. Indeed, clinical trials have found that patients who receive cataract surgery within 6 weeks experience better visual and quality-of-life outcomes ${ }^{8,9}$ and experience fewer adverse events (e.g., falling) ${ }^{9}$ than patients who wait 6 months or longer. Patient satisfaction with wait time follows a similar pattern. Most patients are satisfied with wait times of 3 months or less, and as wait times get longer, the level of dissatisfaction increases. ${ }^{11,15,16}$

Table 2: Summary of studies that examined variables that modify the relation between wait time for cataract surgery and patient outcomes

\begin{tabular}{|c|c|c|c|c|}
\hline Study & $\begin{array}{l}\text { Design } \\
\text { (location) }\end{array}$ & Objective & Result & Quality score \\
\hline \multirow[t]{3}{*}{$\begin{array}{l}\text { Dunn et al, }{ }^{16} \\
1997\end{array}$} & \multirow{3}{*}{$\begin{array}{l}\text { Prospective } \\
\text { cohort study } \\
\text { (Manitoba, } \\
\text { Denmark, } \\
\text { Barcelona) }\end{array}$} & \multirow{3}{*}{$\begin{array}{l}\text { To identify factors } \\
\text { that determine } \\
\text { patient dissatisfaction } \\
\text { with wait time }\end{array}$} & $\begin{array}{l}\text { Cataract symptom score }(p=0.03) \text { and trouble with } \\
\text { vision }(p=0.04) \text { were associated with the perception } \\
\text { that a wait was too long }\end{array}$ & \multirow{3}{*}{$\begin{array}{l}\text { NOS }=5 / 9 \\
\text { (selection } 2 / 4, \\
\text { comparability } 2 / 2, \\
\text { outcome } 1 / 3 \text { ) }\end{array}$} \\
\hline & & & $\begin{array}{l}\text { Patient dissatisfaction with wait time was significantly } \\
\text { predicted by anticipated wait time }\end{array}$ & \\
\hline & & & $\begin{array}{l}\text { Patient satisfaction was not significantly associated } \\
\text { with age, sex, living arrangement, socioeconomic } \\
\text { status, work status, global health status, VF-14 score, } \\
\text { better eye vision and months since diagnosis }\end{array}$ & \\
\hline \multirow[t]{2}{*}{$\begin{array}{l}\text { Conner-Spady } \\
\text { et al, }{ }^{15} 2004\end{array}$} & \multirow[t]{2}{*}{$\begin{array}{l}\text { Prospective } \\
\text { cohort study } \\
\text { (Vancouver) }\end{array}$} & \multirow[t]{2}{*}{$\begin{array}{l}\text { To assess how wait } \\
\text { time predicts patient } \\
\text { satisfaction and } \\
\text { surgical outcomes }\end{array}$} & $\begin{array}{l}\text { Patients were more likely to be satisfied with their wait } \\
\text { time if they rated their maximum acceptable wait time } \\
\text { as }>2 \text { months (OR } 2.40,95 \% \mathrm{Cl} 1.02-5.64) \text {, their actual } \\
\text { wait time was shorter than their maximum acceptable } \\
\text { wait time (OR } 3.86,95 \% \mathrm{Cl} 1.38-10.74 \text { ) or they were } \\
\text { women (OR } 2.08,95 \% \mathrm{Cl} 1.02-4.23 \text { ) }\end{array}$ & \multirow[t]{2}{*}{$\begin{array}{l}\text { NOS }=8 / 9 \\
\text { (selection } 3 / 4, \\
\text { comparability } 2 / 2 \\
\text { outcome } 3 / 3 \text { ) }\end{array}$} \\
\hline & & & $\begin{array}{l}\text { Factors that were not significant predictors of patient } \\
\text { satisfaction: age, first- or second-eye surgery, ocular } \\
\text { comorbidity, driving, perceived urgency, changes in } \\
\text { visual acuity, function or health-related quality of life }\end{array}$ & \\
\hline $\begin{array}{l}\text { Conner-Spady } \\
\text { et al, }{ }^{17} 2005\end{array}$ & $\begin{array}{l}\text { Prospective } \\
\text { cohort study } \\
\text { (Vancouver) }\end{array}$ & $\begin{array}{l}\text { To assess validity of } \\
\text { the Cataract Surgery } \\
\text { Priority Criteria Tool* }\end{array}$ & $\begin{array}{l}\text { The Cataract Surgery Priority Criteria Tool predicted } \\
\text { improvement in visual function assessment }(p=0.007) \\
\text { and visual acuity }\end{array}$ & $\begin{array}{l}\text { NOS }=9 / 9 \\
\text { (selection } 4 / 4, \\
\text { comparability } 2 / 2 \text {, } \\
\text { outcome } 3 / 3 \text { ) }\end{array}$ \\
\hline
\end{tabular}

Note: $\mathrm{OR}=$ odds ratio, $\mathrm{Cl}=$ confidence interval, $\mathrm{NOS}=$ Newcastle-Ottawa scale.

*The Cataract Surgery Priority Criteria Tool is used to assess best corrected vision, glare, ocular comorbidities, reduced visual function, other disabilities, and ability to work and live independently and ability to care for dependents. 
The difference in outcomes between short wait times (less than 6 weeks) and long wait times (more than 6 months) is apparent, yet the outcomes associated with wait times between 6 weeks and 6 months remains unclear. The nature of the relation between wait time and outcomes for this time interval is potentially highly important, in terms of both patient outcome and resource management. If there is no difference in outcomes between wait times of 6 weeks and 6 months, wait time benchmarks may safely be set at 6 months. But if the relation is linear, or even exponential, additional time spent waiting for surgery may have a drastic impact on patient outcomes, and wait time benchmarks must be set accordingly.

In the case of cataract surgery, it is necessary to stress the importance of outcomes experienced by patients during the wait period. We present evidence that vision ${ }^{6-8}$ and quality of life decreases ${ }^{8,9}$ and that the rate of falls increases ${ }^{9}$ among patients during the wait period. There is little empirical evidence regarding postoperative outcomes experienced by patients following different lengths of wait times. However, in the field of ophthalmology it is generally understood that surgery can restore all vision and vision-related quality of life lost due to cataracts regardless of how long the patient has waited for surgery. In addition, the importance of the negative outcomes experienced by patients during the wait period is increased when we consider that wait time, as defined in this review, represents only a portion of the true wait a patient experiences. The Wait Time Alliance acknowledges that a patient's wait begins before the visit to a specialist or surgical booking: it begins when the primary care provider decides that diagnostic testing, clinical intervention or both is needed. ${ }^{35}$ Because the time between referral to and visit with a specialist may actually be longer than the wait time from surgical booking to surgery, ${ }^{36,37}$ the period when patients experience negative visual and quality-of-life outcomes and have an increased risk of adverse events is substantially underestimated under the current definition of wait time.

Our systematic review has a number of potential limitations. First, only 2 randomized controlled trials (total of $5 \mathrm{II}$ patients) and 5 cohort studies were available for us to establish any form of inferences regarding the effect of wait time on patient outcomes. Any inferences are limited by the small samples and low event rates in the study populations. In addition, inferences from systematic reviews are always tempered by the quality of the primary studies. In this instance, both of the included randomized controlled trials were reasonably well conducted, scoring in the mid-range on the Jadad Scale. The interpretation of associations from the observational studies may have been affected by differences in study populations between the studies, differences in definitions of outcomes and different observation periods, especially when comparing wait times of 6 weeks with those exceeding 6 months.

Prioritization tools that incorporate variables that modify the relation between wait time and outcomes, such as the Cataract Surgery Priority Criteria Tool developed by the Western Canada Waiting List Project, may provide the means to prioritize scheduling of surgery in a way that is fair and consistent. ${ }^{17}$ However, further investigation into the factors that affect wait times is necessary, because many modifying variables have been examined only superficially. In regards to outcome modifiers, the findings of our review are limited in that most of the evidence presented is based on expert opinion rather than on empirical investigation.

This article has been peer reviewed.

From the Department of Ophthalmology (Hodge, Albiani, Buhrmann, O'Connor, Blair, Lowcock), University of Ottawa Eye Institute; the Chalmers Research Group (Hodge, Horsley), Children's Hospital of Eastern Ontario Research Institute; and the Faculty of Medicine (Baryla, Belliveau), University of Ottawa, Ottawa, Ont.

\section{Competing interests: None declared.}

Contributors: All of the authors contributed substantially to the design of the study, the acquisition, analysis and interpretation of the data, and the drafting and critical revision of the article for important intellectual content. All of the authors gave final approval of the version to be published.

Acknowledgements: We thank the following individuals for their involvement in our technical expert panel and for providing other advice: MarieJosée Aubin, Lorne Bellan, Hélène Boisjoly, Jeremy Grimshaw, Philip Hooper, Brent MacInnis, David Moher, Howard Schacter and Sanjay Sharma.

This study was requested and funded by the Canadian Institutes of Health Research, through the Toward Canadian Benchmarks for Health Services Wait Times - Evidence, Application and Research Priorities program. The evidence presented in this article was synthesized as I component of a larger systematic review. ${ }^{33}$

\section{REFERENCES}

I. Bell CM, Hatch WV, Cernat G, et al. Cataract surgery. In: Tu JV, Pinfold SP, McColgan $\mathrm{P}$, et al., editors. Access to health services in Ontario: ICES atlas. Toronto: Institute for Clinical Evaluative Sciences; 2005. p. 7I-90. Available: www.ices.on.ca /webpage.cfm?site_id=I\&org_id=67\&morg_id=o\&gsec_id=0\&item_id=2862\&type $=$ atlas (accessed 2007 Feb I2).

2. Klein BE, Klein R, Lee KE. Incidence of age-related cataract over a ro-year interval: the Beaver Dam Eye Study. Ophthalmology 2002;109:2052-7.

3. Moher D, Cook D, Eastwood S, et al. Improving the quality of reports of metaanalyses of randomized controlled trials: the QUOROM statement. Quality of reporting of meta-analyses. Lancet 1999;354:1896-900.

4. Jadad A, Moore R, Carroll D, et al. Assessing the quality of report of randomized clinical trials: Is blinding necessary? Control Clin Trials I996;I7:I-I2.

5. Wells G, Shea B, O'Connell D, et al. The Newcastle-Ottawa Scale (NOS) for assessing the quality of nonrandomized studies in meta-analyses. Proceedings of the 3rd Symposium on Systematic Reviews. Beyond the basics: improving quality and impact; 2000 July 3-5; Oxford. Oxford, 2000.

6. Riley AF, Grupcheva CN, Malik TY, et al. The waiting game: natural history of a cataract waiting list in New Zealand. Clin Experiment Ophthalmol 2001;29:376-80.

7. Leinonen J, Laatikainen $\mathrm{L}$. The decrease of visual acuity in cataract patients waiting for surgery. Acta Ophthalmol Scand I999;77:68I-4.

8. Laidlaw DA, Harrad RA, Whitaker A, et al. Randomised trial of effectiveness of second-eye cataract surgery. Lancet I998;352:925-9.

9. Harwood RH, Foss AJ, Osborn F, et al. Falls and health status in elderly women following first-eye cataract surgery: a randomized controlled trial. BrJOphthalmol 2005;89:53-9.

Io. Goyal R, Shankar J, Sullivan S. Referrals for cataract surgery: Variations between different geographic areas within a Welsh Health Authority. Eye 2004;I8:773-7.

II. Pager CK, McCluskey PJ. Public versus private patient priorities and satisfaction in cataract surgery. Clin Experiment Ophthalmol 2004;32:482-7.

I2. Sarkies N, Everson J, Davies S. Indicator-based audit of cataract surgery in four neighbouring hospitals in East Anglia. Eye I995;9:13-2I.

I3. Ramchandani M, Mirza S, Sharma A, et al. Pooled cataract waiting lists: views of hospital consultants, general practitioners and patients. JR Soc Med 2002;95:598-6oo.

I4. Nijkamp MD, Nuijts RM, Borne B, et al. Determinants of patient satisfaction after cataract surgery in 3 settings. J Cataract Refract Surg 2000;26:1379-88.

I5. Conner-Spady BL, Sanmugasunderam S, Courtright P, et al. Determinants of patient satisfaction with cataract surgery and length of time on the waiting list. $\mathrm{Br} J$ Ophthalmol 2004;88:1305-9.

I6. Dunn E, Black C, Alonso J, et al. Patients' acceptance of waiting for cataract surgery: What makes a wait too long? Soc Sci Med I997;44:I603-Io.

17. Conner-Spady BL, Sanmugasunderam S, Courtright P, et al. The prioritization of patients on waiting lists for cataract surgery. Validation of the Western Canada Waiting List Project cataract priority criteria tool. Ophthalmic Epidemiol 2005;12: $8 \mathrm{I}-90$. 
I8. Hadjistavropoulos H, Snider B, Bartlett G. Measuring the quality of performance in the management of waiting lists: using cataract surgery as an example. Jt Comm J Qual Improv 1998;24:407-22.

I9. Churchill AJ, Vize CJ, Stewart OG, et al. What factors influence cataract waiting list time? BrJOphthalmol 2000;84:429-3I.

20. Hadorn DC, Holmes AC. The New Zealand priority criteria project. Part I: Overview. BMJ I997;3I4:I3I-4

2I. Lundstrom M, Stenevi U, Thorburn W. Assessment of waiting time and priority setting by means of a national register. Int J Technol Assess Health Care I996;12:136-40.

22. Tuft S, Gallivan S. Computer modeling of a cataract waiting list. Br J Ophthalmol 200I; $85: 582-5$.

23. Bellan L, Methan M. The Manitoba Cataract Waiting List Program. CMAJ 200I;164: II77-80.

24. DeCoster C, Carriere K, Peterson S, et al. Surgical waiting times in Manitoba. Winnipeg: Manitoba Centre for Health Policy and Evaluation; 1998.

25. DeCoster C, MacWilliam L, Walld R. Waiting times for surgery: 1997/98 and I998/g9 update. Winnipeg: Manitoba Centre for Health Policy and Evaluation; 2000. Available: www.umanitoba.ca/centres/mchp/reports/pdfs/waits2.pdf (accessed 2007 Feb I2).

26. Derrett S, Devlin N, Hansen P, et al. Prioritizing patients for elective surgery: a prospective study of clinical priority assessment criteria in New Zealand. Int J Technol Assess Health Care 2003;19:9I-105.

27. Hacker J, Stanistreet D. Equity in waiting times for two surgical specialties: A case study at a hospital in the North West of England. JPublic Health (Oxf) 2004;26:56-60.

28. Norregaard JC, Bernth-Petersen P, Alonso J, et al. Variation in indications for cataract surgery in the United States, Denmark, Canada and Spain: Results from the International Cataract Surgery Outcomes Study. Br J Ophthalmol I998;82:I107-II.

29. Noseworthy T, McGurran J, Hadorn D, et al. Waiting for scheduled services in Canada: development of priority-setting scoring system. JEval Clin Pract 2003;9:23-3I
30. Rodriguez-Miguez E, Herrero C, Pinto-Prades JL. Using a point system in the management of waiting lists: the case of cataracts. Soc Sci Med 2004;59:585-94.

3I. Ross M, Avery A, Foss A. Views of older people on cataract surgery options: an assessment of preferences by conjoint analysis. Qual Saf Health Care 2003;12:13-7.

32. Wegener M, Alsbirk P, Hojgaard-Olsen K. Outcome of Iooo consecutive clinic- and hospital-based cataract surgeries in a Danish county. J Cataract Refract Surg I998; 24:II52-6o.

33. Hodge W, Horsley T. A systematic review of waiting times and outcomes for sight restoration. Ottawa: Canadian Institutes of Health Research; 2005. Available: http://chalmersresearch.com/systematic_reviews_our_research_delivery.htm (accessed 2007 Mar 23).

34. Steinberg E, Tielsch J, Schein O, et al. The VF-I4. An index of functional impairment in patients with cataract. Arch Ophthalmol r994;112:630-8.

35. Wait Time Alliance for Timely Access to Health Care. It's about time: achieving benchmarks and best practices in wait time management. Ottawa: Canadian Medical Association; 2005. Available: www.waittimealliance.ca/multimedia/cma/content _images/inside_cma/media_release/pdf/2005/wta-final.pdf (accessed 2007 Feb I2).

36. Hadorn D, Steering Committee of the Western Canada Waiting List Project. Setting priorities for waiting lists: defining our terms. CMAJ 2000;163:857-60.

37. Esmail N, Walker M. Waiting your turn: hospital waiting lists in Canada. Fraser Institute - Critical Issues Bulletin 2005. Available: www.fraserinstitute.ca/admin/ books/chapterfiles/wyt2005.pdf\# (accessed 2007 Feb I2).

Correspondence to: Dr. William Hodge, University of Ottawa Eye Institute, 50I Smyth Rd., Ottawa ON KIH 8L6; whodge@ottawahospital.on.ca 